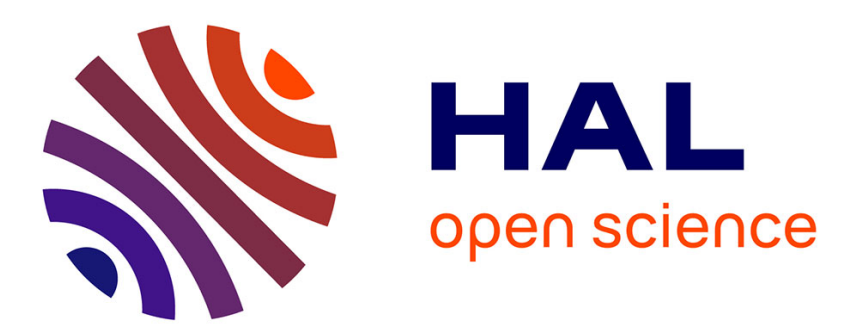

\title{
Antioxidant Properties of Adrenaline in the Presence of Ge-132
}

\author{
G.E. Filonova, E.N. Nikolaevskaya, A.V. Kansuzyan, I.V. Krylova, M.P. \\ Egorov, V.V. Jouikov, M.A. Syroeshkin
}

\section{- To cite this version:}

G.E. Filonova, E.N. Nikolaevskaya, A.V. Kansuzyan, I.V. Krylova, M.P. Egorov, et al.. Antioxidant Properties of Adrenaline in the Presence of Ge-132. European Journal of Organic Chemistry, 2019, 2019 (26), pp.4128-4132. 10.1002/ejoc.201900331 . hal-02181834

HAL Id: hal-02181834

https://hal-univ-rennes1.archives-ouvertes.fr/hal-02181834

Submitted on 14 Nov 2019

HAL is a multi-disciplinary open access archive for the deposit and dissemination of scientific research documents, whether they are published or not. The documents may come from teaching and research institutions in France or abroad, or from public or private research centers.
L'archive ouverte pluridisciplinaire HAL, est destinée au dépôt et à la diffusion de documents scientifiques de niveau recherche, publiés ou non, émanant des établissements d'enseignement et de recherche français ou étrangers, des laboratoires publics ou privés. 


\title{
Ge-132 and the antioxidant properties of adrenaline
}

\author{
Galina E. Filonova, ${ }^{[a, b]}$ Elena N. Nikolaevskaya, ${ }^{*[a]}$ Artem V. Kansuzyan, ${ }^{[a, c]}$ Irina V. Krylova, ${ }^{[a]}$ Mikhail P. \\ Egorov, ${ }^{[a]}$ Viatcheslav V. Jouikov, ${ }^{[c]}$ and Mikhail A. Syroeshkin ${ }^{[a]}$
}

Dedicated to the $85^{\text {th }}$ anniversary of the N.D. Zelinsky Institute of Organic Chemistry RAS

\begin{abstract}
Using cyclic voltammetry, UV and ${ }^{1} \mathrm{H}$ NMR spectroscopy, we have investigated the effect of 2-carboxyethylgermanium (Ge132), the most common germanium-containing dietary supplement, on the antioxidant activity of adrenaline in aqueous solutions. The complex formed by adrenaline and Ge-132 is oxidizable at $400 \mathrm{mV}$ more positive potentials compared to non-coordinated adrenaline which corresponds to its $9 \mathrm{kcal} / \mathrm{mol}$ more difficult oxidation. An equilibrium constant of the complex formation was estimated (1300 $\mathrm{M}^{-1}$ ). It was shown that at the concentrations $<10^{-3} \mathrm{M}$ the complex Ge-132-adrenaline is mostly dissociated to the initial compounds, and the influence of $\mathrm{Ge}-132$ on the antioxidant properties of adrenaline becomes significant only when the former is in an excess. Considering that such concentrations are typical for physiological conditions, this fact can be significant in identifying the mechanism of the biological action of Ge-132 and its interference with the biological catechols.
\end{abstract}

\section{Introduction}

Catechols are a broad group of organic compounds containing 1,2-dihydroxyphenyl moiety. On the one hand, such an easily oxidizable structure forms a large group of antioxidants both of vegetable and of physiological origin [1] involved in regulating the formation of reactive oxygen species. On the other hand, the possibility of binding of metal cations and metalloids with the hydroxyl groups with the formation of stable complexes causes a rich coordination chemistry of these compounds. Of course, the presence of various metals can also affect the antioxidant properties of biologically active catechols [1a]. In humans and animals, catechols can play the role of metabolites in the decomposition of estrogens [2], transmitters (eg, adrenaline, norepinephrine, etc.) [3] etc. These processes are also often associated with the specific behavior of the 1,2-diol fragment.

Among the biogenic catechols, adrenaline is widely known. It is the first hormone synthesized and structurally characterized in 1904 [4]. There is a lot of papers, reviews and patents devoted to the study of adrenaline oxidation under the action of various metal ions. The earliest one describes the adrenaline complexation with bivalent metal ions $\mathrm{Zn}^{2+}, \mathrm{Cd}^{2+}, \mathrm{Ni}^{2+}$ etc. [5]

Recently, our group has shown that adrenaline antioxidant

[a] N.D. Zelinsky Institute of Organic Chemistry, Russian Academy of Sciences, G.E. Filonova, Dr. E.N. Nikolaevskaya*, A.V. Kansuzyan, Dr. I.V. Krylova, Prof. Dr. M.P. Egorov, Dr. M.A. Syroeshkin 119991, Leninsky Prospect, 47, Moscow, Russian Federation E-mail: en@ioc.ac.ru (E.N. Nikolaevskaya)

[b] I.M. Sechenov First Moscow State Medical University, G.E. Filonova 119435, Bolshaya Pirogovskaya 2, Moscow, Russian Federation.

[c] UMR CNRS 6226 ISCR, University of Rennes 1, 35042 Rennes

(France), A.V. Kansuzyan, V.V. Jouikov

E-mail: vjouikov@univ-rennes1.fr (V.V.Jouikov) activity significantly decreases (by one order of magnitude) compared to that of the initial adrenaline when it is complexed with germanium dioxide [6] (scheme 1). Germanium is a physiologically active microelement, heavier group 14 carbon analog with a stable tetravalent state. A distinctive feature of germanium dioxide, in particular in comparison with silicon, is the ability to interact reversibly with catechols under mild, close to physiological, conditions [7].<smiles>CNCC(O)c1ccc(O)c(O)c1</smiles>

Scheme 1. Formation of the complex of germanium dioxide with adrenaline.

By replacing one of the four valences in germanium dioxide with a carboxyethyl function, it is possible to obtain its sesquioxide a widely used and intensively studied biologically active drug commercially known as Ge-132 (scheme 2) [8]. Its various spectrum of activity (including antioxidant) is discussed, [8c], however our results have shown that under physiological conditions Ge-132 can act as an antioxidant mainly in lipid phase in contrast to aqueous media where this activity significantly decreases (scheme 2) [8d].

a

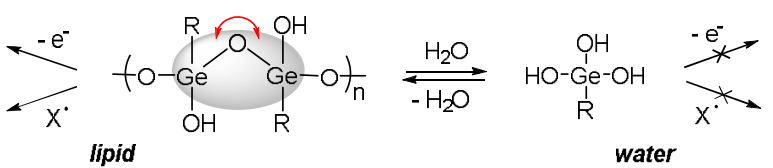
b

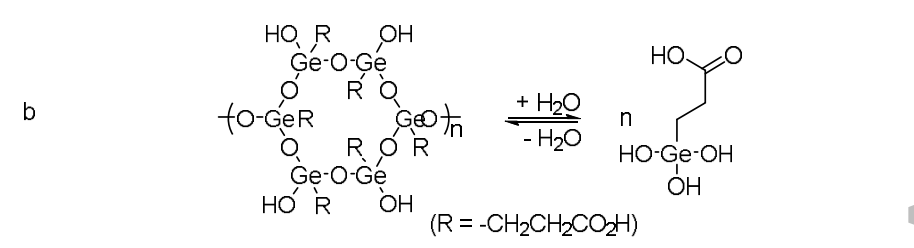

Scheme 2. Antioxidant active (lipid) and non-active (water) forms of Ge-132. 
Moreover, in its water-soluble monomeric triol form, Ge-132 is able to interact with a number of physiological substances: nucleic acids [8c], monosaccharides [9] etc. Recently a complex of adrenaline with Ge-132 (scheme 3) have been isolated and structurally characterized [10]. By analogy with the complex of adrenaline with $\mathrm{GeO}_{2}$, adrenaline-Ge-132 adduct could be expected to have a reduced antioxidant activity relative to the initial adrenaline. In addition, the adduct stability is important under high dilution (physiological conditions). Given the importance of adrenaline in many life-related processes, the present work aims to elucidate this important point.

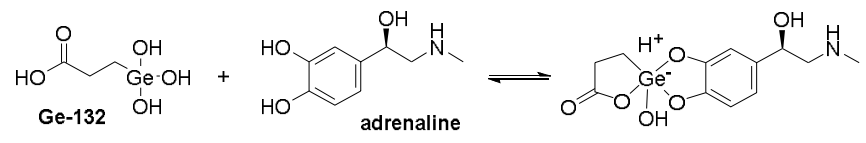

Scheme 3. Formation of the complex of Ge-132 with adrenaline.

\section{Results and Discussion}

The methods of ${ }^{1} \mathrm{H}$ NMR and UV-vis spectroscopy, as well as cyclic voltammetry, are widely used for the study of complexation in solutions [11]. The two latter methods are also used to test antioxidant activity, for example, by evaluating the kinetics of DPPH color disappearance in the reaction with a potential antioxidant (UV-vis spectroscopy [12]) or directly considering the oxidation potential change of the antioxidant determined using voltammetry [13]. Remarkably, these three methods deal with contiguous but different concentration ranges allowing to study the equilibrium processes by independent methods well as to evaluate it in a wide range of concentrations. The results of detailed study of the complexation of Ge-132 with adrenaline in a phosphate buffer solution of close to physiological acidity will be presented below.

\section{${ }^{1} H$ NMR spectroscopy}

The ${ }^{1} \mathrm{H}$ spectrum of $\mathrm{Ge}-132$ in a phosphate buffer solution $(\mathrm{pH}=$ 6.86) at a concentration of $1.3 \cdot 10^{-1} \mathrm{M}$ (Fig. 1a) contains two triplets (1.04 and $1.94 \mathrm{ppm}$ ) belonging to $\mathrm{CH}_{2}-\mathrm{CH}_{2}$ fragments of the molecule. ${ }^{1} \mathrm{H}$ NMR experiment with similar concentrations of adrenaline in aqueous solution is difficult due to the low solubility. When both compounds are present at the same concentrations, the methylene proton signals of Ge-132 shift to 1.30 and 2.04 ppm, respectively (Fig. 1b) corresponding to the complex formation (the equilibrium on Scheme 3 being shifted to the right side). At the same time, along with the complex signals, lowintensity peaks from the protons of unreacted Ge-132 are observed. However, the integral value of these signals relative to the intensity of the corresponding peaks is about $1 \%$ only.

Diluting the reactants 10 times (up to $1.3 \times 10^{-2} \mathrm{M}$ ) causes increasing the intensity of the peaks related to the protons of non-coordinated Ge-132 on its ${ }^{1} \mathrm{H}$ NMR spectrum (Fig. 1c). These changes indicate the complex dissociation (the equilibrium shifting to the left). A similar tendency is observed

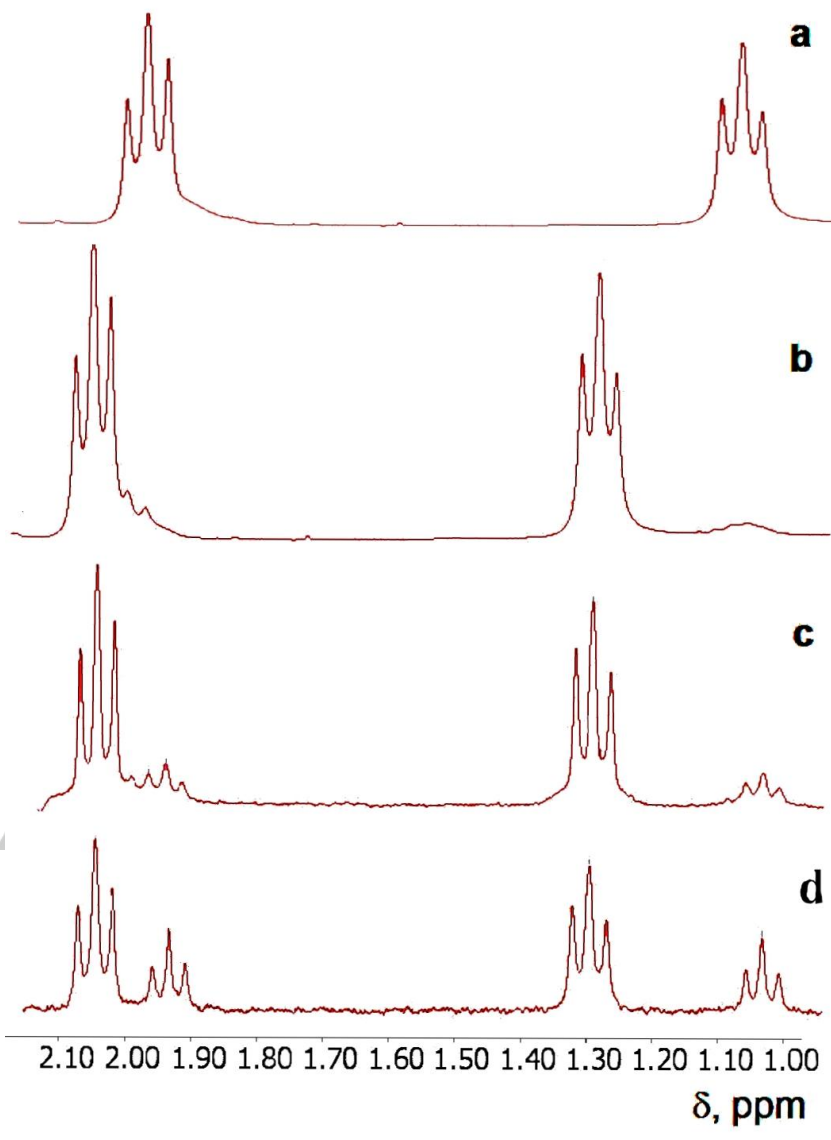

Figure 1. Fragments of ${ }^{1} \mathrm{H}$ NMR spectra of a) Ge-132; b-d) mixture of Ge-132 and adrenaline in $\mathrm{H}_{2} \mathrm{O}$. Concentrations: b) $1.38 \times 10^{-1} \mathrm{M}$; c) $1.3 \times 10^{-2} \mathrm{M}$; d) $\sim 10^{-3}$ M.

for further dilution (Fig. 1d). A series of the experiments in the concentration range $10^{-1}-10^{-3} \mathrm{M}$ allowed us to determine the equilibrium constant of reaction depicted on scheme 3 according to the Ostwald's dilution law as $\mathrm{K}=1300 \pm 70 \mathrm{M}^{-1}$.

At the dilution limit, allowing determining quantitatively the equilibrium components of the reaction using ${ }^{1} \mathrm{H}$ NMR spectroscopy $\left(\sim 10^{-3} \mathrm{M}\right)$, the dissociated and non-dissociated forms of the complex are present in comparable amounts. It should be noted that this is a typical concentration used in cyclic voltammetry.

\section{Cyclic voltammetry}

The CV curve of adrenaline solution $\left(2 \times 10^{-3} \mathrm{M}\right)$ in phosphate buffer $(\mathrm{pH}=6.86)$ at a glassy carbon working electrode is shown in Fig. 2a. It is seen that its oxidation corresponds to a chemically irreversible peak at $0.51 \mathrm{~V}$, and on the reverse scan there is a peak of reduction of adrenalin-quinone (the product of adrenaline oxidation) [14]. Such an easy oxidation of adrenaline reveals its strong antioxidant properties.

At the same time, hampering the adrenaline antioxidant properties following the formation of the complex should correspond to the oxidation peak potential shift to more positive values in the presence of a binding reagent. Indeed, the addition 


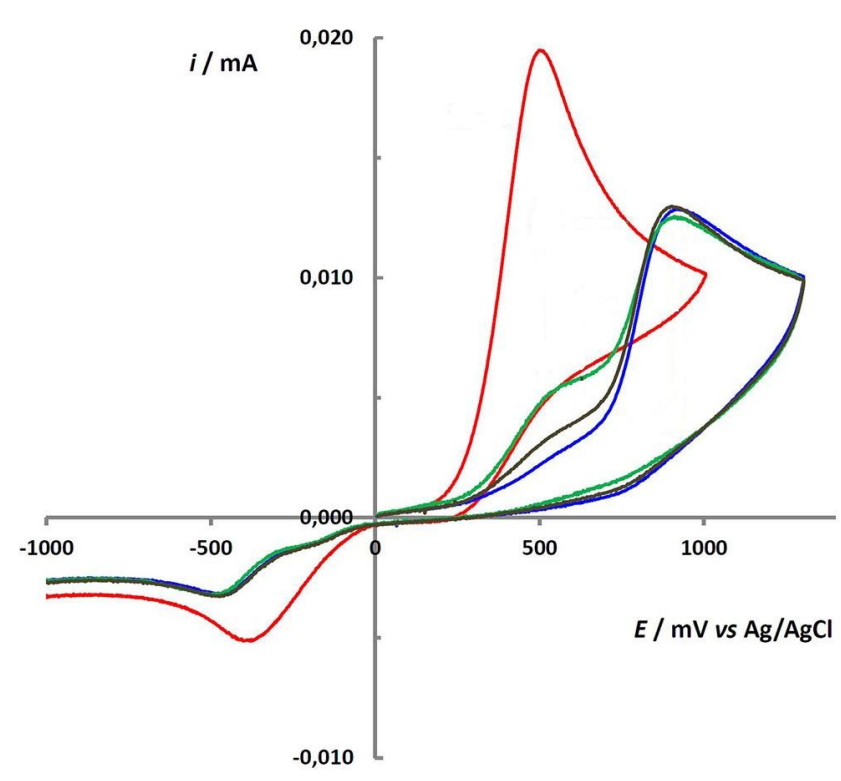

Figure 2. (a) Oxidation of adrenaline $\left(2 \times 10^{-3} \mathrm{M}\right.$, red curve), (b) adrenaline-Ge132 mixture $\left(2 \times 10^{-3} \mathrm{M}+3 \times 10^{-3} \mathrm{M}\right.$, green curve); (c) adrenaline-Ge-132 mixture $\left(2 \times 10^{-3} \mathrm{M}+6 \times 10^{-3} \mathrm{M}\right.$, black curve $)$ and $\left.\mathrm{d}\right)$ adrenaline-Ge-132 mixture $\left(2 \times 10^{-3} \mathrm{M}+9 \times 10^{-3} \mathrm{M}\right.$, blue curve) at a glassy carbon (GC) disk electrode ( $\mathrm{d}=$ $1.7 \mathrm{~mm})$ in phosphate buffer $(\mathrm{pH}=6.86)$. Scan rate $\mathrm{V}=0.1 \mathrm{~V} \mathrm{~s}^{-1} . \mathrm{T}=298 \mathrm{~K}$.

of $3 \times 10^{-3} \mathrm{M} \mathrm{Ge}-132$ to the adrenaline solution is accompanied by the appearance of a new chemically irreversible peak at $0.91 \mathrm{~V}$ (Fig. 2b) corresponding to $9.22 \mathrm{kcal} / \mathrm{mol}$ more difficult oxidation. However, despite the 1.5-fold excess of Ge-132, the oxidation of non-bonded adrenaline (high "shoulder" at $~ 0.51 \mathrm{~V}$ ) is still observed on the CV curve (its current comparable to the current of the complex). It indicates that only part of adrenaline in solution decreases antioxidant properties. Increasing the Ge-132 concentration to $6 \cdot 10^{-3} \mathrm{M}$ (3-fold excess, Fig. 2c) provokes the decrease of this arm and a relative increase of the current of the oxidation peak of the complex. In the presence of $9 \times 10^{-3} \mathrm{M} \mathrm{Ge}$ 132 (4.5-fold excess, Fig. 2d), non-bonded adrenaline in solution is almost invisible and only Ge-132-adrenaline complex is observed. This feature reflects weakr antioxidant properties of the Ge-132-adrenaline complex compared to adrenaline.

Thus, the data of voltammetry correlate well with the NMR results. It was shown that in the concentration range $\sim 10^{-3} \mathrm{M}$, the complex of Ge-132-adrenaline is largely dissociated (the equilibrium 3 is noticeably shifted to the left). The complex has thus significantly reduced antioxidant properties compared to the initial adrenaline. An excess of Ge-132 is required for complex formation.

\section{UV-Vis spectrophotometry}

The standard method of assessing the antioxidant activity and of comparing the potential antioxidants between them is considering their interaction with a stable free radical diphenylpicrylhydrazyl (DPPH) [12]. Moreover, due to the intense color of DPPH in its free form, spectrophotometry is a convenient method to follow the reaction of a potential antioxidant with DPPH. Such interactions are monitored by disappearance of the DPPH color. A more intensive
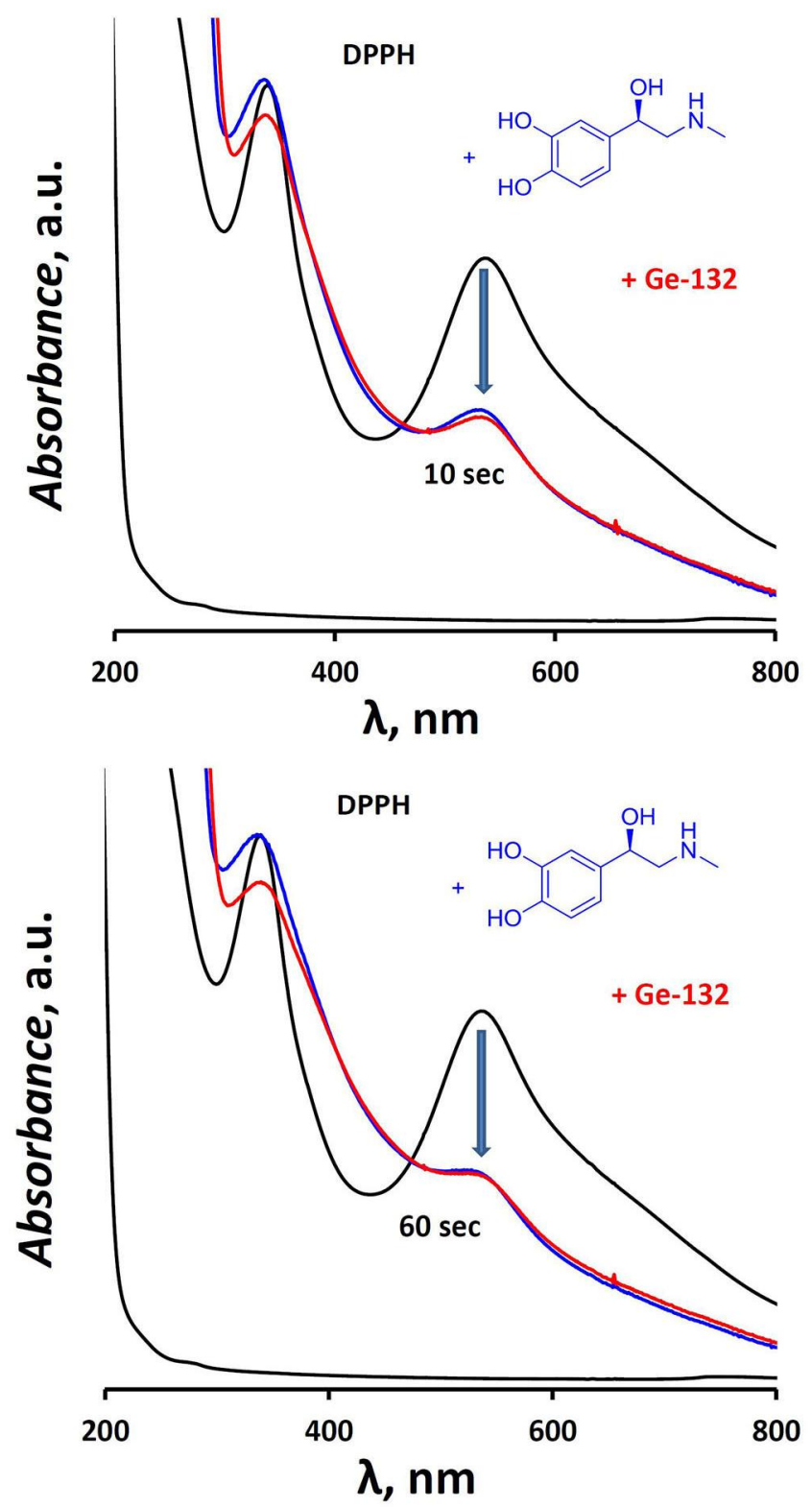

Figure 3. UV-vis spectra of DPPH $\left(1 \times 10^{-4} \mathrm{M}\right.$, black $)$ in phosphate buffer $(\mathrm{pH}=$ $6.86)$ in the presence of equimolar amount of adrenaline $\left(1 \times 10^{-4} \mathrm{M}\right.$, blue $)$ and adrenaline-Ge-132 mixture $\left(1 \times 10^{-4} \mathrm{M}+1 \cdot 10^{-4} \mathrm{M}\right.$, red $)$ after (upper) $10 \mathrm{sec}$ and (lower) $60 \mathrm{sec}$

discoloration of DPPH will correspond to a higher antioxidant activity of the substrate tested. The typical concentrations used in spectrophotometry are $10^{-4} \mathrm{M}$ and below. According to ${ }^{1} \mathrm{H}$ NMR spectroscopy and cyclic voltammetry, dealing with one order of magnitude higher concentrations and even more concentrated solutions, it was possible to assume that in this case the effect of $\mathrm{Ge}-132$ on the antioxidant properties of adrenaline would be decreased. The UV spectra of $1 \times 10^{-4} \mathrm{M}$ $\mathrm{DPPH}$ in phosphate buffer $\mathrm{pH}=6.86$ are presented in fig. 3 (black line). Its intense color corresponds to the $\pi-\pi^{*}$ transition 
at $520 \mathrm{~nm}$. In the presence of an equimolar amount of adrenaline, this peak decreases many times within 10 seconds (Fig. 3, upper, blue line) and becomes hardly noticeable after 60 seconds (Fig. 3, lower, blue line). Taking into account that the UV-spectroscopic method of evaluating the antioxidant activity of a potential antioxidant is based on the estimation of DPPH absorption 30 minutes after mixing them, this is evidence of very strong antioxidant properties of adrenaline. The experiment performed with adrenaline in the presence of Ge-132 (Fig. 3, red lines) shows almost completely identical results without any noticeable inhibition of the interaction of catechol with the free radical.

\section{Conclusions}

The data of ${ }^{1} \mathrm{H}$ NMR spectroscopy, cyclic voltammetry and UV spectrophotometry show that the complex of adrenaline and carboxyethylgermanium Ge-132 has significantly reduced antioxidant properties compared to the initial adrenaline. However, dilution of the solution of this complex in aqueous media to the concentrations of $10^{-4} \mathrm{M}$ or lower causes its dissociation, and the effect of Ge-132 on the antioxidant properties of the catechol cannot be detected anymore.

In general, the hydrolyzed form of $\mathrm{Ge}-132$ in water solution can be considered as a structural analogue of $\mathrm{y}$-aminobutyric acid containing a germane-triol fragment capable to reversible complexation and chelation with a number of organic (in particular, 1,2-diols) and inorganic molecules. Undoubtedly, in many cases various aspects of biological activity of Ge-132 (extensively discussed in the literature) may be associated with this phenomenon. To our opinion - taking into account that the complexes of Ge-132 with catechols have been characterized by various spectral methods (including X-ray crystallography), substantial diversion of the essential reactions of biological catechols in the presence of Ge-132 should be carefully considered.

\section{Experimental Section}

Adrenaline (epinephrine) was purchased from Aldrich and used without further purification. DPPH (Fluka) was used as received. Ge-132 has been prepared from $\mathrm{HGeCl}_{3}$ and ethyl acrylate according to ref. [15]. Phosphate buffer solutions ( $\mathrm{pH}=6.86$ ) were purchased from Ecroskhim and dissolved in $1 \mathrm{~L}$ of distilled water before use. Thus prepared solution contained $3.389 \mathrm{~g}$ of $\mathrm{KH}_{2} \mathrm{PO}_{4}$ and $3.533 \mathrm{~g}$ of $\mathrm{Na}_{2} \mathrm{HPO}_{4}$.

${ }^{1} \mathrm{H}$ NMR $(300 \mathrm{MHz})$ spectra were recorded on Bruker $\mathrm{AV} 300$ in $\mathrm{H}_{2} \mathrm{O}$ at ambient temperature. UV-Vis spectra were registered using Agilent 8453 instrument using a $10 \mathrm{~mm}$ quartz cell. Cyclic voltammetry was carried out using a PC-piloted digital potentiostat IPC-Pro-MF (Econix). A standard thermostated $\left(T=25 \pm 0.5^{\circ} \mathrm{C}\right) 10 \mathrm{ml}$ electrochemical cell was used in a three-electrode configuration. As a working electrode, GC $(1.7 \mathrm{~mm})$ disk was used, polished before each run; a Pt wire was used as an auxiliary electrode. The potentials are referred to the $\mathrm{AgCl} / \mathrm{KCl}_{\text {sat }}$ electrode separated from the analyte by an electrolytic bridge filled with the same solution. All measurements were carried out under dry argon.

\section{Acknowledgments}

This work was supported by Russian Science Foundation (№ 18-73-10180). A.V.K. thanks the Embassy of France in Moscow for scholarship support in the framework of the program "Vernadski“.

Keywords: Ge-132 • adrenaline • cyclic voltammetry • DPPH • NMR spectroscopy

[1] a) E. Monzani, S. Nicolis, S. Dell'Acqua, A. Capucciati, C. Bacchella, F. Zucca, E. Mosharov, D. Sulzer, L. Zecca, L. Casella, Angew. Chem. Int. Ed., accepted manuscript; b) A.M. Pisoschi, A. Pop, Eur. J. Med. Chem., 2015, 97, 55-74.

[2] J.L. Bolton, E. Pisha, F. Zhang, S. Qiu, Chem. Res. Toxicol., 1998, 11, 1113-1127; b) J.L. Bolton, L. Shen, Carcinogenesis, 1996, 17, 925929.

[3] a) Y.H. Song, .S Mardh, O. Nyren, L. Loof, Scand. J. Gastroenterol., 1988, 23, 35-41; b) L.B. Sigola, R.B. Zinyama, Immunology, 2000, 100, 359-363; c) J.M. Delfs, Y. Zhu, J.P. Druhan, G. Aston-Jones, Nature 2000, 403, 430-434; d) D. Devos, L. Defebvre, R. Bordet, Fundam. Clin. Pharmacol. 2010, 24, 407-421.

[4] F. Stolz, Über adrenalin und alkylaminoacetobrenzcatechin, Ber. dtsch. Chem. Ges., 1904, 37, 41-49.

[5] A. Gergely, T. Kiss, G. Deák, I.Sóvágó, Inorg. Chim. Acta, 1981, 56, 35-40; b) B. Grgas-Kužnar, VI. Simeon, O.A. Weber, J. Inorg. Nucl. Chem, 1974, 36, 2151-2154; c) R.F. Jameson, W.F.S. Neillie, J. Inorg. Nucl. Chem., 1966, 28, 2667-2675; d) E. Mentasti, E. Pelizzetti, G. Saini, J. Inorg. Nucl. Chem., 1976, 38, 785-788.

[6] N. Nikolaevskaya, A.V. Kansuzyan, G.E. Filonova, V. A. Zelenova, V.M Pechennikov, I.V. Krylova, M.P. Egorov, V.V. Jouikov, M.A. Syroeshkin, Eur. J. Inorg. Chem. 2019, 676-681.

[7] E.N. Nikolaevskaya, E.A. Saverina, A.A. Starikova, A. Farhati, M.A. Kiskin, M.A. Syroeshkin, M.P. Egorov, V.V. Jouikov, Dalton Trans., 2018, 47, 17127-17133.

[8] a) V.F. Mironov, E.M. Berliner, T.K. Gar, Russ. J. Gen. Chem., 1967, 37, 911-912; b) V.F. Mironov, Main Group Metal Chem. 1989, 12, 355 c)T. Wada; T. Hanyu, K. Nozaki, K. Kataoka, T. Kawatani, T. Asahi, N. Sawamura, Biol. Pharm. Bull., 2018, 5, 749-753; d) A.A. Vishtorskaya, E.A. Saverina, V.M. Pechennikov, I.V. Krylova, A.V. Lalov, M.A. Syroeshkin, M.P. Egorov, V.V. Jouikov, J. Organomet. Chem., 2018, 858, 8-13; e) Y. Shimada, K. Sato, T. Takeda, Y. Tokuji, Biol. Trace Elem. Res., 2018, 181, 164-172; f) E. Kim, S. Hwang, J.D. Yoon, E. Jeung, E. Lee, D.Y. Kim, S. Hyan, Journal of Reproduction and Development, 2017, 63, 581-590; j) Y. Liu, L. Hou, Q. Li, Z. Jiang, W. Gao, Y. Zhu, H. Zhang, Environ. Technol., 2016, 38, 85-93.

[9] Y. Shimada, K. Sato, Y. Tokuji, T. Nakamura, Carbohydr. Res., 2015, 407, 10-15.

[10] T. Nakamura, Y. Shimada, T. Takeda, K. Sato, M. Akiba, H. Fukaya, Future Med. Chem., 2015, 7, 1233-1246.

[11] F. Diederich, D. Griebel, J. Am. Chem. Soc., 1984, 106, 8037-8046.

[12] a) C. Lopez-Alarcon, A. Denicola, Anal. Chim. Acta, 2013, 763, 1-10; b) M. Carocho, I.C.F.R. Ferreira, Food Chem. Toxicol., 2013, 51, 15-25.

[13] a) J. Hoyos-Arbelaez, M. Vazquez, J. Contreras-Calderon, Food Chem. 2017, 221, 1371-1381; b) J. Sochor, J. Dobes, O. Krystofova, B. Ruttkay-Nedecky, P. Babula, M. Pohanka, T. Jurikova, O. Zitka, V. Adam, B. Klejdus, R. Kizek, Int. J. Electrochem. Sci. 2013, 8, 8464 8489; c) A.M. Pisoschi, C. Cimpeanu, G. Predoi, Open Chem. 2015, 13, 824-856.

[14] A.C. Anitha, K. Asokan, C. Sekara, Electrochim. Acta, 2017, 237, 4453.

[15] N. Kakimoto, M. Akiba, T. Takada, Synthesis, 1985, 272-274 